04

\title{
Качественный анализ вин и виноматериалов методами поляризованно-люминесцентной голографии на основе использования их оптических поляризационных спектров
}

\author{
(C) В.И. Тарасашвили, А.Л. Пурцеладзе, С.С. Петрова, В.Г. Шавердова, М.В. Тарасашвили
}

Лаборатория голографической записи и обработки информации, Институт кибернетики, Грузинский технический университет,

0186 Тбилиси, Грузия

e-mail: v_tarasashvili@mail.ru

Поступила в редакцию 18.11 .2019 г.

В окончательной редакции 18.11.2019 г.

Принята к публикации 06.12.2019 г.

\begin{abstract}
Идентификация и классификация вин реализована на основе совместной обработки различных видов поляризационных спектров мультиплексных динамических люминесцентных голограмм Денисюка, полученных на базе образцов исследуемой винодельческой продукции (конкретных марок вина). Для анализа были отобраны спектр люминесценции восстановленного мнимого изображения объекта, спектр степени анизотропии люминесценции реконструированного поля объекта и спектр коэффициента эллиптичности люминесценции реконструированного поля объекта. Проведено экспериментальное исследование поляризационных свойств мультиплексных голограмм Денисюка, полученных в люминесцентном фотоанизотропногиротропном материале с использованием линейно-поляризованного когерентного источника света. Наблюдалась поляризационно-голографическая память. Описан эксперимент по идентификации образцов, проведенный с целью проверки возможности использования поляризационных спектров для распознавания вин.
\end{abstract}

Ключевые слова: спектрально-голографический портрет вина, оптические поляризационные спектры, идентификация, поляризационно-голографическая память.

DOI: $10.21883 /$ OS.2020.03.49063.307-19

\section{Введение}

Методы и средства поляризационной голографии находят все более широкое применение при изучении состава и свойств веществ и материалов, как при проведении научных исследований, так и при решении разнообразных прикладных задач $[1-4]$. В работе [5] нами впервые было предложено использовать применительно к поляризационной голографии среды, спектр люминесценции которых однозначно реагирует на состояние поляризации возбуждающего излучения (эффект Вейгерта) [6]. Использование поляризационночувствительных люминесцентных регистрирующих сред открыло новые возможности и направления в поляризационной голографии, новые пути регистрации и преобразования электромагнитных волн. К таким возможностям относятся экологический мониторинг и контроль пищевых продуктов, продовольственного сырья и лекарственных препаратов, клиническая лабораторная диагностика, контроль некоторых видов промышленной продукции. В качестве примера можно привести работу авторов данной статьи [7], где методами поляризационно-люминесцентной голографии были исследованы поляризационно-люминесцентные характеристики сред для голографии на базе различных битуминозных материалов - сырая нефть из различ- ных буровых Сацхенинского месторождения и автомобильные бензины различных марок. Был проведен качественный анализ сред методами поляризационнолюминесцентной голографии, получена мультиплексная отражательная голограмма Денисюка [8] в люминесцентном фотоанизотропно-гиротропном материале на базе образцов углеводородных топлив и обнаружена зависимость состояния поляризации реконструированного изображения от поляризации восстанавливающего пучка, что может трактоваться как поляризационная память люминесцентной голограммы Денисюка [4]. Были получены также поляризационные спектры степени поляризации фотолюминесценции образцов в зависимости от их химического состава и структуры. Это позволило создать векторный спектральноголографический образ (портрет), характеризующий углеводородные топлива, включая такие признаки, как качество и географическое происхождение, а также марку автомобильных бензинов. Результаты проведенных исследований представляют интерес в нефтяной промышленности при диагностике и контроле качества топлив, их идентификации, а также экологического мониторинга.

Целью данной работы является идентификация и классификация винодельческой продукции (конкретных марок вина) методами поляризационно-люминесцентной 
голографии на основе использования совместной обработки различных видов поляризационных спектров люминесцентных мультиплексных, динамических голограмм Денисюка. Вино является одним из наиболее сложных по химическому составу алкогольных напитков. В состав вина входят сахара, органические кислоты, различные летучие вещества, фенольные соединения, макро- и микроэлементы. В результате взаимодействия этих составляющих между собой и образуется специфический вкус и аромат (букет) вина. Идентификация предусматривает выявление различий между винами по химическому составу, физическим и физикохимическим свойствам. Из-за большого экономического и социального значения виноделия очень важным является развитие аналитических методов классификации и идентификации вин прежде всего для защиты торговых марок, предотвращения фальсификаций вин и искажений информации о качестве вина и его географическом происхождении.

В настоящее время системы контроля вин действуют на национальном и международном уровнях. Существует целый ряд нормативных документов, регламентирующих процедуры контроля вина [9]. Однако существующие методики регламентируют именно процедуры измерения концентрации различных веществ, но не затрагивают идентификацию и классификацию вин, необходимую для установления подлинности и выявления фальсификатов. Для идентификации и классификации вин эффективным является исследование их изотопного состава, но это требует использования весьма дорогостоящей аппаратуры (изотопных масс-спектрометров) и больших затрат времени на подготовку и проведение анализов. Поэтому интенсивно разрабатываются и развиваются более доступные инструментальные методы идентификации и классификации вин. Наиболее перспективными представляются методы, основанные на использовании хроматографии [10] и оптической спектроскопии. Достоинствами оптико-спектральных методов являются экспрессность, очень простая пробоподготовка, в большинстве случаев сводящаяся к разбавлению, относительная простота анализа и доступность оборудования. Поэтому актуальным является выбор наиболее информативных оптических методов и оптических спектров различного типа, их измерение, создание базы спектральных данных характерных образцов винодельческой продукции, разработка аттестованных методик измерения и рекомендаций по математической обработке и проведении на ее основе идентификации вин.

В ряде работ в качестве экспресс-метода для установления подлинности вин использовалась люминесцентная спектроскопия. В качестве примера можно привести работы [11-13], где спектры люминесценции, зарегистрированные при фронтальном возбуждении, использовались для установления происхождения, марки и года урожая.

Основными веществами, вызывающими люминесценцию, являются присутствующие в вине различные фе- нольные соединения, а в красных винах, кроме того, антоцианы (красящие пигменты растительного происхождения, присутствующие, в частности, в красных сортах винограда).

Однако в приведенных работах для классификации вин используется только один тип спектров - скалярные спектры. Это налагает некоторые ограничения, так как использование различных типов спектров и методов позволяет увеличить объем собираемой информации и распространить метод на более разнообразные выборки образцов.

В представленной работе впервые предложено в качестве экспресс-метода для установления подлинности вин использовать методы поляризационно-люминесцентной голографии, где для исследования векторных характеристик анизотропно-гиротропных голограммных люминесцентных сред используется поляризационнолюминесцентная спектроскопия - а именно векторные свойства излучения, находящие свое выражение в состоянии поляризации испускаемого света (явления поляризованной люминесценции).

Благодаря основополагающим работам С.И. Вавилова, В.Л. Левшина, П.П. Феофилова изучение и использование явления поляризованной люминесценции для решения как фундаментальных, так и прикладных задач получило очень широкое распространение. Выяснились возможности, которые дает поляризованная люминесценция при исследовании строения поглощающих и излучающих систем [14-16]. Выяснение природы поляризационных спектров позволило сознательно подойти к рассмотрению спектров различных химических соединений. Было показано,что поляризационные спектры каждого индивидуального соединения вполне своеобразны и могут привлекаться в качестве новой, дополнительной характеристики при решении аналитических задач. Так, например, для решения одной из основных проблем люминесцентного анализа - проблемы установления идентичности двух веществ.

В данной работе приводятся результаты исследования коллоидных систем, в частности образцов конкретных марок вин методами поляризационно-люминесцентной голографии. При этом основное внимание уделено совместному использованию различных видов оптических спектров поляризационных люминесцентных мультиплексных голограмм Денисюка, созданию своеобразного векторно-спектрального голографического образа (портрета) вин [17]. В данном случае спектральноголографический портрет вина - это набор определенных видов оптических спектров поляризационных люминесцентных мультиплексных голограмм Денисюка, полученных на базе образцов исследуемой винодельческой продукции, характеризующих конкретную марку вина или виноматериал, включая такие признаки, как сортовой состав винограда и его географическое происхождение. 


\section{Материалы и методика измерений}

В качестве объектов исследования были выбраны образцы белых и красных вин различных марок ведущих грузинских производителей: № 1 Марани Кондоли Мцване-Киси, винодельческий р-н Кахетия, сортовой состав винограда: Мцване 50\% и Киси 50\%; № 2 БадагониЦинандали, р-н Кахетия, сортовой состав винограда: Ркацители $85 \%$ и Мцване 15\% и № 3 Бадагони-Саперави розовое сухое, р-н Кахетия, сортовой состав винограда: Саперави $100 \%$.

Исследования поглощения проб образцов проводились в кварцевых кюветах. Спектры поглощения получены на спектрофотометре Specord UV-VIZ, модифицированном для поляризационных измерений. Количественные измерения фотоанизотропных характеристик люминесцентных мультиплексных динамических голограмм Денисюка проводились на голографическом поляризационном спектрофлуориметре, собранном нами на основе монохроматора МДР-4 с дифракционной решеткой в качестве диспергирующего элемента для выделения монохроматического излучения в заданном спектральном диапазоне. Отличительной особенностью этого прибора является возможность записи и реконструкции динамических, поляризационных люминесцентных голограмм; установка была снабжена поляризационными призмами Глана, что давало возможность проводить измерения фотоанизотропных и фотогиротропных характеристик люминесцентных мультиплексных отражательных голограмм, для построения их поляризационных спектров различных видов.

Как известно многие флуорофоры, присутствующие в винах, например, различные соединения фенола, склонны к образованию упорядоченных структур на поверхности жидкого образца; особенно существенным этот эффект становится для смеси вина с водой. В связи с этим становится существенной регистрация люминесценции именно поверхностного слоя, поэтому при исследовании вин, по мнению ряда исследователей, является предпочтительным использование (наряду с традиционной) также и фронтальной (front-face) схемы регистрации люминесценции. Фронтальная схема позволяет также исключить влияние эффекта внутреннего фильтра, который проявляется в традиционной схеме и заключается в поглощении в кювете возбуждающего излучения и излучения люминесценции [18].

Схема голографического поляризационного спектрофлуориметра с фронтальной (front-face) схемой регистрации и измерения поляризационных спектров люминесцентных мультиплексных динамических голограмм Денисюка приводится на рис. 1.

На исследуемых образцах вин проведена серия экспериментов по поляризационной записи динамических люминесцентных голограмм с использованием линейно-поляризованного когерентного излучения лазеpa LSR 405 NL-50 $(\lambda=405 \mathrm{~nm})$. На пути возбуждающего

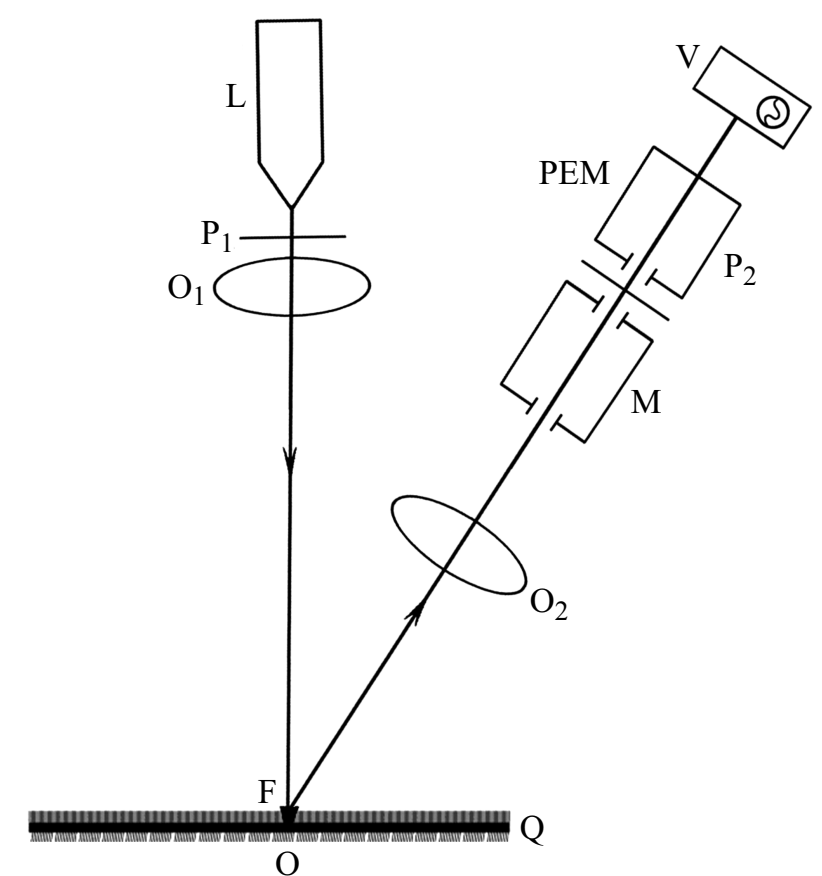

Рис. 1. Схема голографического поляризационного спектрофлуориметра с фронтальной (front-face) схемой регистрации и измерения поляризационных спектров люминесцентных мультиплексных динамических голограмм Денисюка: $\mathrm{F}$ - образец вина (открытая поверхность); $\mathrm{L}$ - лазер; $\mathrm{O}_{1}, \mathrm{O}_{2}$ - объективы; М - монохроматор МДР-4; $\mathrm{P}_{1}$ - линейный поляризатор; $\mathrm{P}_{2}$ - анализатор (призмы Глана); Q - динамическая поляризационно-люминесцентная голограмма Денисюка; О анизотропно-гиротропный объект; РЕМ-РМТ-31 - фотоприемник; V - измерительное устройство.

пучка устанавливался линейный поляризатор $\mathrm{P}_{1}$ (призма Глана). Голограммы записывались по классической оптической схеме, предложенной Ю.Н. Денисюком [8]. В качестве анизотропно-гиротропного объекта О служило плоское зеркало с внешним алюминированием поляризующий оптический элемент, удовлетворяющий теоретическим условиям, необходимым для адекватной реконструкции векторного поля объекта [4]. Объект располагался непосредственно за пробами образца (открытая поверхность вина) и освещался линейнополяризованным излучением лазера через слой голограммной среды. Отраженные от объекта волны распространялись назад к этому же слою. В результате наложения падающего и отраженного излучений возникает система стоячих волн - интерференционное поле во встречных пучках, передающее все особенности волнового фронта объекта, т. е. динамическая поляризационнолюминесцентная голограмма Денисюка Q $[19,20]$. Луч, соответствующий реконструированному мнимому изображению объекта, для поляризационного анализа проецировался на входную щель монохроматора М, откалиброванного по пропусканию и по длинам волн с точностью $\pm 1 \mathrm{~nm}$. После прохождения монохроматора $\mathrm{M}$ 
(где происходит отбор длин волн из требуемого интервала спектра люминесценции и блокирование возбуждающих длин волн), он попадал на линейный поляризатор $\mathrm{P}_{2}$ (анализатор), имеющий возможность поворачиваться относительно электрического вектора возбуждающего излучения. Далее пучок попадает на чувствительный фотоприемник РЕМ-РМТ-31, откалиброванный по спектральной чувствительности и скомпенсированный по темновому току. Электрический сигнал с РМТ поступает на измерительное устройство V. Снимая показания измерительного устройства при различных положениях диспергирующего элемента (дифракционной решетки) и при ориентациях анализатора $\mathrm{P}_{2}\left(0\right.$ и $\left.90^{\circ}\right)$ относительно электрического вектора возбуждающего излучения, получаем данные для построения выбранных видов поляризационных спектров люминесцентной голограммы. Поворот поляризации лазерного излучения приводил к повороту плоскости поляризации PL, что вызывало модуляцию интенсивности PL после прохождения через анализатор $\mathrm{P}_{2}$. Зависимость состояния поляризации реконструированного изображения от поляризации восстанавливающего пучка может трактоваться как поляризационная память люминесцентной голограммы Денисюка (поляризационно-голографическая память).

Степень анизотропии поляризации люминесценции реконструированного поля объекта рассчитывалась по формуле $r=\frac{I_{0}-I_{90}}{I_{0}+2 I_{90}}$, коэффициент эллиптичности поляризации реконструированного поля объекта - по формуле $K_{e}=\frac{I_{90}}{I_{0}}$. Здесь $I_{0}$ и $I_{90}-$ интенсивности взаимно перпендикулярно поляризованных компонент люминесценции интенсивностей реконструированного поля объекта.

При исследовании ставилась задача выбора видов поляризационных спектров голограмм, имеющих характерные особенности, по совокупности которых возможно установление значимых различий между образцами конкретных марок вин. Такая совокупность параметров оптических поляризационных спектров представляет собой векторный спектрально-голографический образ (портрет) вина.

Были отобраны следующие виды спектров поляризационных мультиплексных голограмм Денисюка: 1) спектр интенсивности люминесценции восстановленного мнимого изображения объекта (параметр I), 2) поляризационный спектр степени анизотропии люминесценции реконструированного поля объекта (параметр $r$ ) и 3) поляризационный спектр коэффициента эллиптичности люминесценции реконструированного поля объекта (параметр $K_{e}$ ). При этом руководствовались критериями информативности и стабильности спектров, а именно:

- выбранные параметры спектров должны различаться между собой для образцов конкретных марок вин;

- для одного и того же образца эти спектры должны быть как можно более стабильны во времени.

Как было отмечено выше, поляризационные спектры каждого индивидуального соединения являются вполне

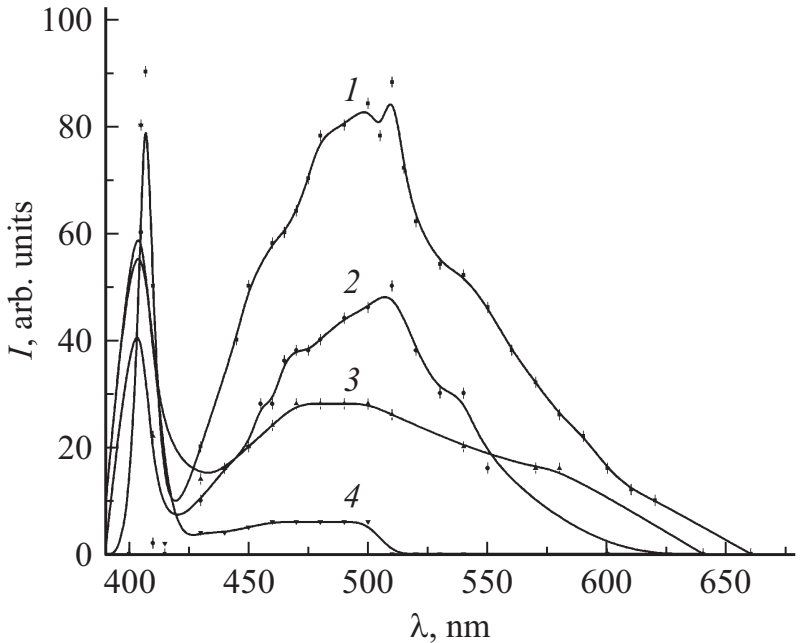

Pис. 2. Спектры интенсивности люминесценции восстановленного мнимого изображения объекта (параметр I): кривая 1 - образец № 1 Марани Кондоли Мцване-Киси, винодельческий р-н Кахетия, сортовой состав винограда: Мцване $50 \%$ и Киси 50\%; кривая 2 - образец № 2 БадагониЦинандали, р-н Кахетия, сортовой состав винограда: Ркацители $85 \%$ и Мцване 15\%; кривая 3 - образец № 3 БадагониСаперави розовое сухое, р-н Кахетия, сортовой состав винограда: Саперави 100\%; кривая $4-$ фальсификат полученной в разбавленной дистиллированной воде в соотношении 1:5 в пробе подлинного образца № 1.

своеобразными и могут привлекаться в качестве новой, дополнительной характеристики при решении поставленной в данной работе аналитической задачи - показать возможности подхода, основанного на использовании векторных спектрально-голографических портретов, состоящих из различных видов спектров поляризационных люминесцентных мультиплексных голограмм Денисюка, полученных на базе исследуемой винодельческой продукции (конкретных марок вина), для решения задач по распознаванию вин и виноматериалов. В данной работе обработке подвергаются оптические спектры целиком, что повышает информативность и достоверность анализа; отметим также, что поляризационные спектры могут оказаться значительно более характерным свойством люминесцирующего вещества, чем спектр люминесценции, часто недостаточно характерный, или спектр поглощения, который может быть искажен посторонними веществами, присутствующими в исследуемой смеси.

Экспериментально были получены выбранные виды поляризационных спектров восстановленного мнимого изображения объекта с мультиплексных голограмм, зарегистрированных в образцах конкретных белых и красных вин различных марок. Спектральные портреты были получены при одинаковых условиях записи мультиплексных поляризационно-люминесцентных голограмм с использованием линейно поляризованного излучения лазера LSR 405NL-50 $(\lambda=405 \mathrm{~nm}, 36 \mathrm{~mW})$. 


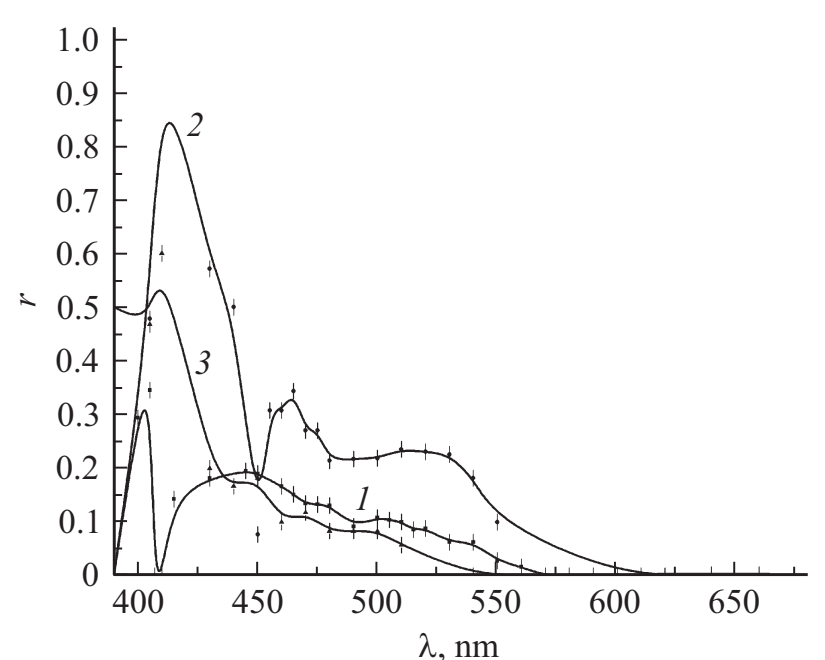

Рис. 3. Спектры степени анизотропии люминесценции реконструированного поля объекта (параметр $r$ ): кривая 1 - образец № 1 Марани Кондоли Мцване-Киси, винодельческий р-н Кахетия, сортовой состав винограда: Мцване 50\% и Киси 50\%; кривая 2 - образец № 2 Бадагони-Цинандали, р-н Кахетия, сортовой состав винограда: Ркацители 85\% и Мцване 15\%; кривая 3 - образец № 3 Бадагони-Саперави розовое сухое, p-н Кахетия, сортовой состав винограда: Саперави $100 \%$.

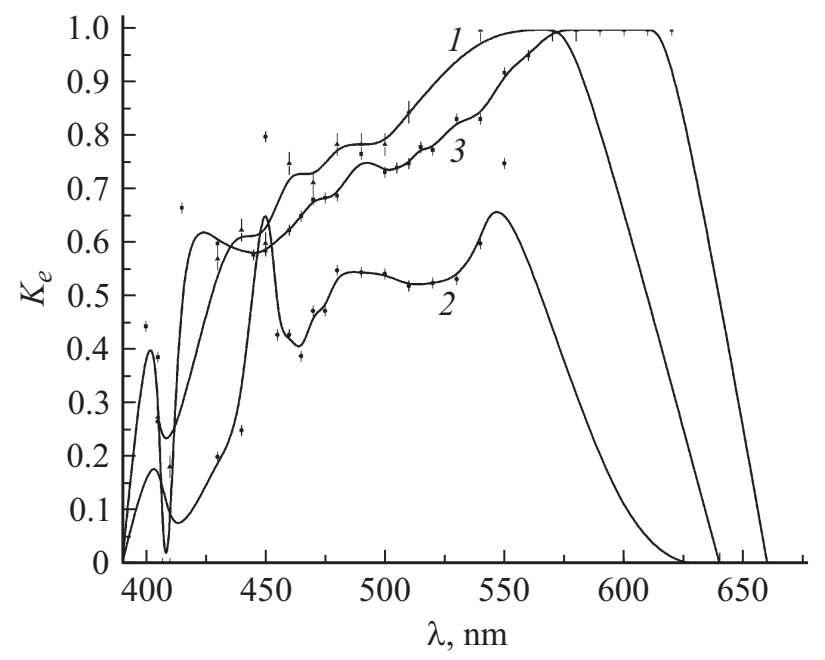

Рис. 4. Спектры коэффициента эллиптичности люминесценции реконструированного поля объекта (параметр $K_{e}$ ): кривая 1 - образец № 1 Марани Кондоли Мцване-Киси, винодельческий р-н Кахетия, сортовой состав винограда: Мцване $50 \%$ и Киси 50\%; кривая 2 - образец № 2 БадагоныЦинандали, р-н Кахетия, сортовой состав винограда: Ркацители $85 \%$ и Мцване $15 \%$; кривая 3 - образец № 3 БадагоныСаперави розовое сухое, р-н Кахетия, сортовой состав винограда: Саперави $100 \%$.

На рис. 2 приведены спектры интенсивности люминесценции восстановленного мнимого изображения объекта (параметр I), зарегистрированные в различных поляризационно-чувствительных средах на базе образцов исследуемой винодельческой продукции.
На рис. 3 показаны поляризационные спектры степени анизотропии люминесценции реконструированного поля объекта (параметр $r$ ), зарегистрированные в различных поляризационно-чувствительных средах на базе образцов исследуемой винодельческой продукции.

Рисунок 4 демонстрирует поляризационные спектры коэффициента эллиптичности люминесценции реконструированного поля объекта (параметр $K_{e}$ ), зарегистрированных в различных поляризационно-чувствительных средах на базе образцов исследуемой винодельческой продукции.

Приведенные рисунки демонстрируют наличие широкого спектра поляризованной люминесценции от 400 до $650 \mathrm{~nm}$ для всех образцов выбранных белых и красных вин различных марок. Это объясняется тем, что электронная система вин очень разветвленная (как было отмечено выше, вино является одним из наиболее сложных по химическому составу алкогольных напитков). При возбуждении длиной волны $405 \mathrm{~nm}$ происходят многочисленные электронные переходы с возбужденного уровня на основной; это благоприятствует возникновению широкого спектра индуцированной поляризованной люминесценции мультиплексных голограмм Денисюка.

Как следует из анализа экспериментально полученных нами поляризационных спектров, с изменением марок образцов вин наблюдаются характерные изменения абсолютной величины анизотропно-гиротропных параметров отражательных динамических голограмм - $I, r$ и $K_{e}$. Максимальные значения интенсивности поляризованной люминесценции (параметр I) имеют пробы вина образца № 1; максимальные значения абсолютных величин степени анизотропии люминесценции (параметр $r$ ) имеют пробы вина образца № 2, в то время как пробы вина образца № 3 имеют минимальные значения этого параметра. По значению абсолютных величин степени анизотропии люминесценции можно судить о природе молекул, находящихся в пробе [21]. Отметим также, что у исследуемых марок вин перемена знака параметра $r$ не наблюдается; отсюда следует, что при фиксированной длине волны возбуждающего света угол $\alpha$ между поглощающим и излучающим осцилляторами меньше $90^{\circ}$ [22].

Из анализа экспериментальных результатов видно, что у поляризационных спектров коэффициента эллиптичности люминесценции реконструированного поля объекта (параметр $K_{e}$ ), полученных для поляризационночувствительных люминесцентных регистрирующих сред различного химического строения (различный сортовой состав винограда), имеются спектральные области, где значения коэффициента эллиптичности поляризации реконструированного поля объекта $K_{e} \approx 1$. Это означает, что в заданном спектральном диапазоне состояние поляризации реконструированного поля объекта превращается в циркулярно поляризованное. Если коэффициент эллиптичности равен нулю, состояние поляризации восстановленного поля объекта имеет линейную поляризацию (адекватную поляризации регистрирующего 
когерентного излучения). В промежутке $0<K_{e}<1$ состояние поляризации реконструированного поля объекта эллиптическое.

Приведенные результаты демонстрируют наличие высокой информативности каждого вида поляризационных спектров и могут привлекаться в качестве новой, дополнительной характеристики при решении аналитических задач проведения идентификации и классификации проб вин и винодельческой продукции на основе векторного спектрально-голографического портрета вин. В ходе исследования измеряемых спектров все они показали хорошую стабильность (в пределах $2 \%$ ).

Используя спектральный портрет вин, состоящий из совокупности нескольких видов поляризационных спектров, возможно выявление винодельческой продукции, подлинность которой вызывает сомнения. Такое выявление может быть осуществлено методом сравнения между собой спектров проб с образцами спектров аналогов; обработкой спектров анализируемых образцов, сравнением по признакам, характерным для данного вида спектров.

Приведенные на рис. 2 спектры интенсивности люминесценции (параметр I) восстановленного мнимого изображения объекта проб подлинных образцов № 1, 2, 3 (кривые 1, 2, 3 соответственно), а также фальсификата, полученного путем разбавления дистиллированной водой в соотношении 1:5 пробы подлинного образца № 1 (кривая 4), показывают, что интенсивность люминесценции подлинных проб винодельческой продукции значительно отличается от интенсивности люминесценции образцов фальсификатов, для которых люминесценция и значения параметров $r$ и $K_{e}$ практически отсутствуют.

\section{Заключение}

Проведен качественный анализ вин и виноматериалов методами поляризационно-люминесцентной голографии. Идентификация и классификация вин реализуется на основе совместной обработки различных видов поляризационных спектров люминесцентных мультиплексных динамических голограмм Денисюка, полученных на базе образцов исследуемой винодельческой продукции (конкретных марок вина). Для исследованных вин наиболее информативными оказались следующие оптические спектры голограмм: 1) спектр интенсивности люминесценции восстановленного мнимого изображения объекта (параметр I), 2) поляризационный спектр степени анизотропии люминесценции реконструированного поля объекта (параметр $r$ ) и 3) поляризационный спектр коэффициента эллиптичности люминесценции реконструированного поля объекта (параметр $K_{e}$ ). Они позволили устанавливать воспроизводимые различия между разными марками вин, приготовленных из разного сорта винограда, даже выпущенными на одном предприятии (№ 1 Бадагоны-Цинандали и № 3 Бадагоны-Саперави розовое сухое). Используя эти спектры, оказалось возможным определять взаимное расположение поглощающих и излучающих осцилляторов в образце (значение угла $\alpha$ между ними; знак параметра $r$ ), установить связь между симметрией молекул в образце и значения абсолютных величин степени анизотропии индуцированной фотолюминесценции (параметр $r$ ) [21,22].

Проведено экспериментальное исследование поляризационных свойств люминесцентной отражательной голограммы Денисюка, полученной в люминесцентнофотоанизотропно-гиротропном материале с использованием линейно поляризованного когерентного света. Обнаружена зависимость состояния поляризации реконструированного изображения от поляризации восстанавливающего пучка (параметр $K_{e}$ ) - поляризационноголографическая память динамической люминесцентной голограммы Денисюка [4]. Это создает перспективы для новых прикладных и научных применений отражательных голограмм Денисюка.

Приведенные результаты показывают возможность подхода, основанного на использовании векторного спектрально-голографического портрета образцов конкретной винодельческой продукции, состоящей из оптических поляризационных спектров выбранного вида, для решения задач по распознаванию вин (конкретных марок) и виноматериалов.

В заключение отметим, что разработанная в данной работе концепция векторного спектрально-голографического портрета, представляющая собой совокупность различных видов поляризационных спектров мультиплексных люминесцентных голограмм Денисюка, однозначно характеризующая вина и виноматериалы, также может представлять интерес для использования метода при идентификации, классификации, диагностики и контроля качества других объектов, представляющих собой сложные коллоидные системы.

\section{Список литературы}

[1] Какичашвили Ш.Д. // Открытия, изобретения. 1979. № 38.

[2] Тарасашвили В.И., Пурцеладзе А.Л. // Опт. и спектр. 2007. T. 103. № 6. С. 1046.

[3] Желтов А.Я., Степанов Б.И., Шавердова В.Г. // ЖПС. 1990. T. 52. C. 280.

[4] Пуриеладзе А.Л., Тарасашвили В.И., Шавердова В.Г., Петрова С.С. // ЖПС. 2014. Т. 81. № 1. С. 65.

[5] Шавердова В.Г., Петрова С.С., Пуриеладзе А.Л., Тарасашвили В.И., Оболашвили Н.З. // Опт. и спектр. 2017. T. 123. № 3. C. 458. doi 10.7868/S0030403417090288

[6] Weigert F. // Verh. Dtsch. Phys. Ges. 1919. V. 21. P. 479.

[7] Тарасашвили В.И., Петрова С.С., Пуриеладзе А.Л., Шавердова В.Г., Оболашвили Н.3. // Опт. и спектр. 2018. T. 125. № 4. C. 535. doi 10.21883/OS.2018.10.46707.18

[8] Денисюк Ю.Н. // Опт. и спектр. 1963. Т. 15. № 4. С. 522.

[9] Compendium of International Methods of Analysis of Wines and Musts. V. 1-2. 2014.

[10] Якуба Ю.Ф., Темердашев 3.А. // Аналитика и контроль. 2015. T. 19. № 4. C. 288. 
[11] Mousdis G., Mellou F. // Food Authentication: Management, Analysis, and Regulation. Wiley, 2017. P. 298.

[12] Boggia R. et al. // J. Food Sci. Technol. 2017. V. 54. № 8. P. 2422.

[13] Tan J. et al. // Food Chemistry. 2015. V. 184. P. 30.

[14] Левшин Л.В., Салецкий А.М. Люминесценция и ее измерения. Молекулярная люминесценция. М.: МГУ, 1989. 272 с.

[15] Шлезингер М.A. Люминесцентный анализ. М.: Физ-мат. литература, 1961. $401 \mathrm{c.}$

[16] Svirikhin M.S., Puzyk M.V., Borisov A.N. // Opt. Spectrosc. 2016. V. 121. N 1. P. 343.

[17] Левин А.Д., Нагаев А.И., Садагов А.Ю., Карахотин С.Н. // Аналитика и контроль. 2018. Т. 22. № 2. С. 147. doi 10.15826/analitika.2018.22.2.001

[18] Gebala S. et al. // Polish J. Food and Nutrition Science. 2007. V. 57. N 3. P. 363.

[19] Танин Л.В., Танин В.А. // Мир голографии. 2017. Т. 3. № 1. C. 4.

[20] Толстик А.Л. // Мир голографии. 2017. Т. 3. № 1. С. 24.

[21] Бабушкин A.A. и др. Методы спектрального анализа. М.: МГУ, 1962. 509 c.

[22] Вавилов С.И. Собр. соч. М. 1952. 129 с. 